\title{
CONGENITAL CUTIS LAXA WITH PNEUMONIA: A RARE CASE IN PEDIATRIC PRACTICE
}

P. Ramu1, R. Bhavani Shankar², A. Deepak Kumar³

\section{HOW TO CITE THIS ARTICLE:}

P. Ramu, R. Bhavani Shankar, A. Deepak Kumar. "Congenital Cutis Laxa with Pneumonia: A Rare Case in Pediatric Practice". Journal of Evolution of Medical and Dental Sciences 2015; Vol. 4, Issue 11, February 05; Page: 1889-1892, DOI: $10.14260 /$ jemds/2015/273

ABSTRACT: BACKGROUND: Cutis laxa (Dermatomegaly) - rare heterogeneous group of an orphan disease related to connective tissues, affecting many organ systems of human body requiring a multidisciplinary approach.

KEYWORDS: Cutis laxa, Congenital, Acquired, Autosomal recessive, Autosomal dominant, X- linked.

INTRODUCTION: CASE CHARACTERISTICS: A 1 Year 3 months male child admitted for pneumonia found to have unusually loose skin and increased skin folds all over.

OBSERVATIONS: A 1 year 3months first born male child of non-consanguineous parents brought with chief complaints of cold, cough-1week, fever -5 days, and breathlessness -1 day. A thorough physical examination revealed signs of right upper lobe pneumonia as well as unusually loose skin, more skin folds, hooked nose, right inguinal hernia, aged facial appearance and the child not attained age appropriate mile stones especially motor (not attained standing without support till 15 months of age). But the joints are normal. At the time of admission, in an attempt to secure an intravenous line, we noticed unusually loose skin and with great difficulty intravenous line was secured. Convinced with the characteristic clinical findings diagnosed to be a case of "congenital cutis laxa" and incidental pneumonia. The child was treated for 1 week as inpatient and had pediatric surgical and dermatological advise for follow up at discharge.

DISCUSSION:1,2,3 Cutis laxa (Latin for loose or lax skin) also known as Generalized Elastolysis / Dermatomegaly / Dermatolysis / Dermatochalasia / Generalized elastorrhexis / Pachydermatocele is an Orphan disease (a very rare disease) related to a heterogeneous connective tissue disorder in which the skin becomes inelastic and hangs loosely in folds. It cis estimated that Cutis laxa affects 1 in every 2000,000 babies and to date only less than 400 cases reported worldwide broadly classified as congenital and acquired cutis laxa. The clinical presentation of congenital variety depends upon the mode of inheritance as:

1. Autosomal dominant,

2. Autosomal recessive, and

3. X-linked 'recessive patterns.

Autosomal dominant congenital cutis laxa (ADCL) is genetically heterogeneous and shows clinical variability. Mutations in the elastin gene (ELN) have been described.

Autosomal recessive cutis laxa is a genetically heterogeneous condition is divided into several sub types (Such as ARCL1A, ARCL1B, ARCL1C, ARCL 2A, ARCL3) and is a combined disorder of N- and O-linked glycosylation has been described in children with congenital cutis laxa in association with severe central nervous system involvement, brain migration defects, seizures, and hearing loss. ARCL3 
or DeBarsy syndrome comprises of overlapping features with ARCL2A and ARCL2B. The recessive forms are the most common and are usually more severe than the other forms.

Autosomal recessive cutis laxa type 1 is caused b I a defective gene on chromosome 5 . Symptoms include emphysema; diverticula in the esophagus, /duodenum, and bladder; lax and dislocated joints; tortuous arteries; hernias; lysyl oxidase deficiencies; and retarded growth.

Autosomal recessive cutis laxa type 2 is also inherited as a recessive trait. In addition to the loose skin, this form of the disease is characterized by bone abnormalities, the delayed joining of the cranial (skull) bones, hip dislocation, curvature of the spine, flat feet, and excessive tooth decay. A serine to proline amino acid substitution in the fibulin 5 (FBLN5) gene has been associated with problems in normal elastogenesis, resulting

In a recessive form of cutis laxa (elastolysis) in humans. The X-linked form is currently classified in the group of copper transport diseases. The precise cause is unknown, but it may be due to abnormal elastin metabolism resulting in markedly reduced dermal elastin content. Sex-linked cutis laxa is caused by a defective gene on the $\mathrm{X}$ chromosome.

In both the inherited type and the acquired type, the internal organs are frequently involved. Acquired Cutis laxa (elastolysis) may be preceded by an inflammatory rash, (Erythema multi forme) or it may develop spontaneously.

Loose skin, the primary and most obvious symptom of these diseases, is caused by underlying defects in connective tissue structure, which also cause more serious internal problems in vocal cords, bones, cartilage, blood vessels, bladder, kidney, digestive system, and lungs. The loose skin is particularly obvious on the face, and children with the disorder look sad or mournful.

In addition to loose skin, its symptoms are mild mental retardation, loose joints, bone abnormalities (Like hooked nose, pigeon breast, and funnel breast), frequent loose stools, urinary tract blockages, and deficiencies in lysyl oxidase, an enzyme required for the formation of properly functioning connective tissue. (But the defective gene does not code for lysyl oxidase.) Its symptoms are loose, hanging skin, missing elastic fibers, premature aging, and pulmonary emphysema. Only a few families are known with cutis laxa inherited as a dominant trait.

Diagnosis: The signs of cutis laxa are very obvious and easy to diagnose by examining the skin. The determination type of cutis laxa can be made by information about the associated symptoms and by family histories.

Differential Diagnosis: 1) Ehlers - Danlos syndrome, 2) Gerodermia osteodysplastica 3) Lenz Majewski Syndrome, 4) Hyperostotic dwarfism, 5) SCARF Syndrome ( Skeletal abnormalities, Cutis Laxa, Craniostenosis, ambiguous genitalia, retardation, facial abnormalities, Costello syndrome) and 6, MACS syndrome (Macrocephaly, Alopecia, cutis laxa and scoliosis).

Treatment: As on today there is no definitive therapy for this rare disorder and the treatment includes largely supportive and symptomatic. Once the diagnosis is made treatment and follow up should be made on a multi-disciplinary approach including Cardiologists, Gastroenterologists, Rheumatologists, Dermatologists, Plastics surgeons and Paediatricians depending upon the patients age and associated complications. 


\section{CASE REPORT}

Treatment for complications include surgical treatment for hernias, beta blockers to prevent growth of aortic aneurysms and symptomatic treatment for pulmonary complications like emphysema. Though Plastic surgery for the loose skin gives good results but recurrence is common. Cutis laxa patients should be advised to avoid environmental triggers such as cigarette smoking, exposure to dust which worsens pulmonary complications and avoid sun bathing which damages the skin.

Prognosis: prognosis varies with the type of disorder and largely depends on type and extent of others systemic and internal organ involvement.

Figure 1: Right inguinal Hernia.

Figure 2: Laxity of Skin.

Figure 3: Increased Skin folds allover and sub coastal retractions.

Figure 4: Aged facial appearance, Sad or mournful facial appearance and hooked nose.

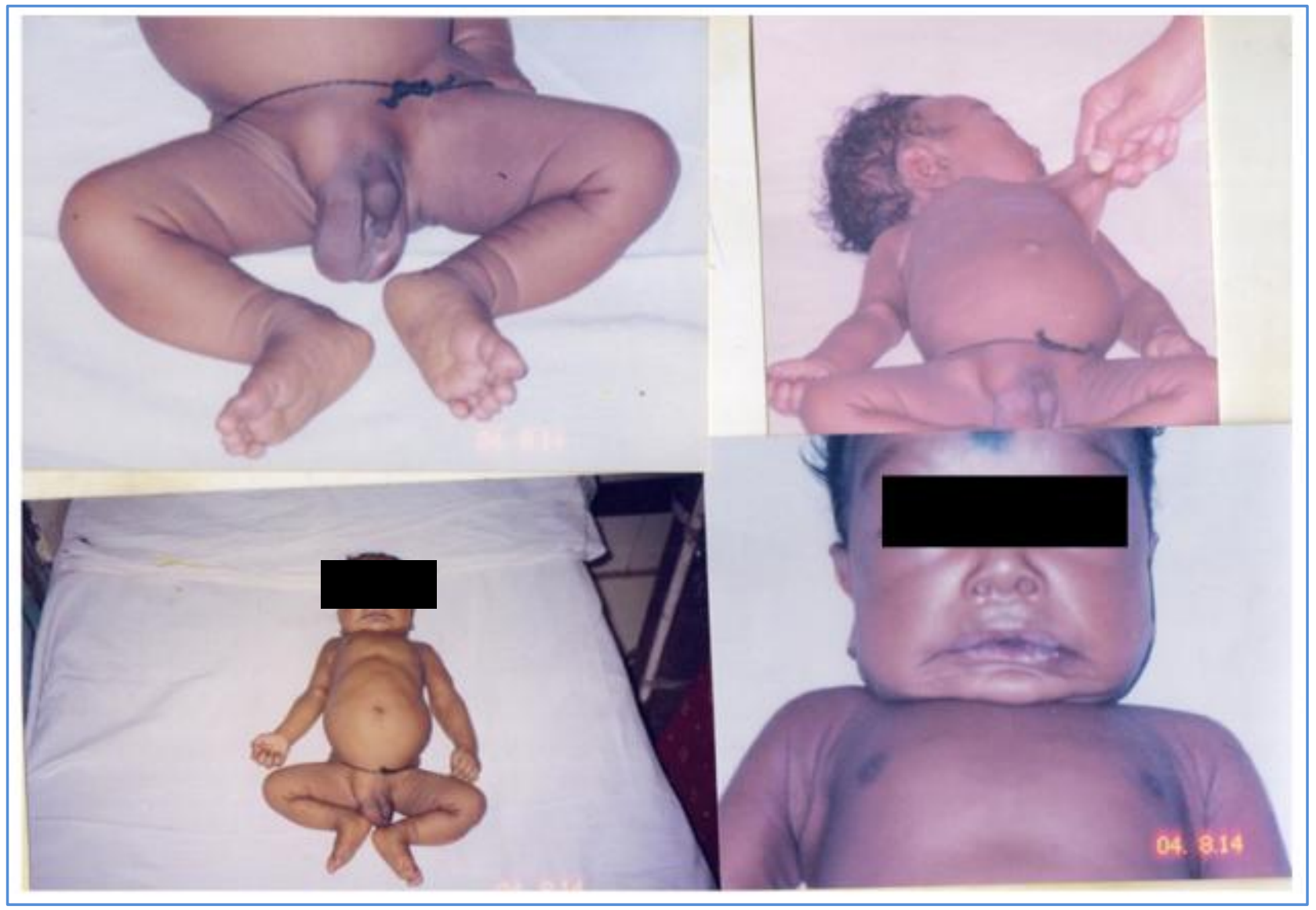

Fig. 1, 2, 3 and 4

Photographs of our Case - Congenital Cutis laxa 


\section{REFERENCES:}

1. Jump up Rapini, Ronald P Bolognia, Jean L Jorizzo, Joseph L. (2007). Dermatology: 2-Volume Set. St. Louis: Mosby. ISBN 1-4160-2999-0.

2. Jump Up James, William; Berger, Timothy; Elston, Dirk (2005). Andrews' Diseases of the Skin: Clinical Dermatology. (10th) ed. Saunders. Page 515. ISBN 0-7216-2921-0.

3. Nelson textbook of Pediatrics $19^{\text {th }}$ edition.

\section{AUTHORS:}

1. P. Ramu

2. R. Bhavani Shankar

3. A. Deepak Kumar

\section{PARTICULARS OF CONTRIBUTORS:}

1. Assistant Professor, Department of Paediatrics, Andhra Medical College, King George Hospital, Visakhapatnam.

2. Former Assistant Professor, Department of Paediatrics, Andhra Medical College, King George Hospital, Visakhapatnam.

3. Assistant Professor, Department of Paediatrics, Andhra Medical College, King George Hospital, Visakhapatnam.

\section{NAME ADDRESS EMAIL ID OF THE CORRESPONDING AUTHOR:}

Dr. P. Ramu, Door No. 14-1-122/13,

FF-3, Rajasagi Residency, Nowroji Road, Maharanipeta, Visakhapatnam-530002, A. P. E-mail: drpramu73@gmail.com

Date of Submission: 13/01/2015.

Date of Peer Review: 14/01/2015.

Date of Acceptance: 28/01/2015.

Date of Publishing: 05/02/2015. 